Western University

Scholarship@Western

Aboriginal Policy Research Consortium International (APRCi)

2011

Rethinking the "Best Interests" of the Child: Voices from Aboriginal Child and Family Welfare Practitioners

Maureen Long

Rene Sephton

Follow this and additional works at: https://ir.lib.uwo.ca/aprci

Part of the Social Work Commons

Citation of this paper:

Long, Maureen and Sephton, Rene, "Rethinking the "Best Interests" of the Child: Voices from Aboriginal Child and Family Welfare Practitioners" (2011). Aboriginal Policy Research Consortium International (APRCi). 339.

https://ir.lib.uwo.ca/aprci/339 
This article was downloaded by: [University of Western Ontario]

On: 30 October 2012, At: 09:08

Publisher: Routledge

Informa Ltd Registered in England and Wales Registered Number: 1072954 Registered

office: Mortimer House, 37-41 Mortimer Street, London W1T 3J H, UK

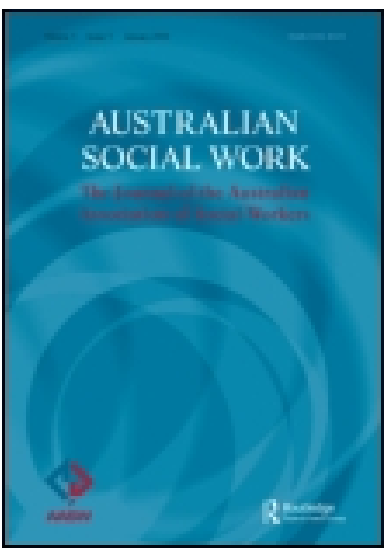

\title{
Australian Social Work
}

Publication details, including instructions for authors and subscription information:

http:// www.tandfonline.com/loi/ rasw20

\section{Rethinking the "Best Interests" of the Child: Voices from Aboriginal Child and Family Welfare Practitioners}

\author{
Maureen Long ${ }^{a} \&$ Rene Sephton ${ }^{b}$ \\ a Social Work and Social Policy, La Trobe University, Bundoora, \\ Victoria, Australia \\ ${ }^{b}$ Victorian Aboriginal Child Care Agency, East Brunswick, Victoria, \\ Australia \\ Version of record first published: 24 Feb 2011.
}

To cite this article: Maureen Long \& Rene Sephton (2011): Rethinking the "Best Interests" of the Child: Voices from Aboriginal Child and Family Welfare Practitioners, Australian Social Work, 64:1, 96-112

To link to this article: http:// dx. doi.org/ 10.1080/ 0312407X. 2010.535544

\section{PLEASE SCROLL DOWN FOR ARTICLE}

Full terms and conditions of use: http://www.tandfonline.com/page/terms-andconditions

This article may be used for research, teaching, and private study purposes. Any substantial or systematic reproduction, redistribution, reselling, loan, sub-licensing, systematic supply, or distribution in any form to anyone is expressly forbidden.

The publisher does not give any warranty express or implied or make any representation that the contents will be complete or accurate or up to date. The accuracy of any instructions, formulae, and drug doses should be independently verified with primary sources. The publisher shall not be liable for any loss, actions, claims, proceedings, demand, or costs or damages whatsoever or howsoever caused arising directly or indirectly in connection with or arising out of the use of this material. 


\title{
Rethinking the "Best Interests" of the Child: Voices from Aboriginal Child and Family Welfare Practitioners
}

\author{
Maureen Long ${ }^{a}$ \& Rene Sephton ${ }^{b}$ \\ ${ }^{a}$ Social Work and Social Policy, La Trobe University, Bundoora, Victoria, Australia; ${ }^{b}$ Victorian \\ Aboriginal Child Care Agency, East Brunswick, Victoria, Australia
}

\begin{abstract}
In Victoria, recent reforms to the child and family welfare system, through the introduction of the Children Youth and Families Act (2005), have significantly strengthened the principle of the "best interests" of the child. Giving substance to the principle, this legislation defines a set of standards and a practice framework to guide its application. How this is to be applied is of particular interest to the Aboriginal child and family welfare sector, given that the principle of best interests has historically underpinned the removal of thousands of Aboriginal and Torres Strait Islander children from their families on the basis of their race (Bamblett, 2006). This paper presents the findings of a qualitative research study that aimed to identify an Aboriginal perspective on the best interests principle as it applies to Victorian Aboriginal children. In-depth interviews were conducted with six experienced Aboriginal child and family welfare practitioners. The outcomes of this study highlight the distinct cultural perspectives that inform Aboriginal child and family welfare practice and raise a number of concerns in regard to an ongoing ethnocentric application of the principle by mainstream service providers. Key findings of the study are discussed, including the importance of increasing understanding of Aboriginal child-rearing practices, recognising that there is a distinct Aboriginal understanding of what constitutes a best interests framework, and the implications of this for both Aboriginal and mainstream child and family welfare practice. The paper discusses these findings within the context of recent Victorian legislative reform, which promotes Aboriginal self-determination, and argues that more work is needed to ensure Aboriginal perspectives are incorporated into service provision to Aboriginal children and families if we are truly to meet the best interests of Aboriginal children.
\end{abstract}

Keywords: Best Interests Principle; Indigenous; Aboriginal; Child and Family Welfare

It is estimated that tens of thousands of Aboriginal and Torres Strait Islander children were removed from their families and raised in institutions or fostered-out to non-Aboriginal people. This was seen as a way of promoting the "best interests"

\footnotetext{
Correspondence to: Dr Maureen Long, School of Social Work and Social Policy, La Trobe University Bundoora, Victoria 3086, E-mail: M.Long@latrobe.edu.au Accepted 24 October 2010
} 
of the child. It made little difference what the Aboriginal family situation really was or how the children were cared for, because being Aboriginal was, in itself, seen as a reason to regard children as "neglected". (Bamblett \& Lewis, 2006, p. 43)

The way in which the best interests of Aboriginal children have been understood and acted upon in Australia has been the cause of much pain and shame in our history. The introductory quote clearly identifies the impact this principle has had historically for Australian Aboriginal families. Using the guise of the principle, acts of colonisation were carried out through successive policies and practices that, according to the National Inquiry into the Separation of Aboriginal and Torres Strait Islander Children from their Families (1997), resulted in the forcible removal of 10 to $30 \%$ of Aboriginal children between 1910 and 1970. The belief that it was in the best interests of Aboriginal children to be removed from their families and assimilated into "white" society is a clear indication of the way the principle can be interpreted by the values of a decision maker or society at any given time. As pointed out by D'Souza (1993), the fact that this system has largely been dismantled does not mean that the child and family welfare service system has rid itself of this history. Among other intimations, the rate of child protection intervention in the lives of Aboriginal communities and their children still continues at a disproportionate rate to that of non Indigenous children (Australian Institute of Health and Welfare, n.d). More concerning is the prevalence of second (or subsequent) generation removal occurring in more than one in three cases of parents who were themselves removed as children (National Inquiry into the Separation of Aboriginal and Torres Strait Islander Children from their Families, 1997). It is thus of utmost importance that there is a shift towards a system that breaks rather than repeats the cycles of trauma and removal present within Aboriginal communities since invasion.

\section{The Best Interests of the Child}

The United Nations (UN) endorsed the Declaration of Human Rights in December 1948 , but it was 11 years later before it was decided that special protections were required to protect the interests of children, with the development of the Declaration of the Rights of the Child (UN, 1959). A further 30 years later, the UN adopted the International Convention of the Rights on the Child (UN, 1989). The 1989 Convention on the Rights of the Child (UNCRC) embodies four general principles: (a) the best interests of the child as a primary consideration in all actions affecting children; (b) no discrimination; (c) the child's right to life, survival, and development; and (d) the right to express their views freely. However, the UNCRC does not offer a "precise" definition, nor explicitly outline common factors of the best interests of the child, but stipulates that:

The best interests must be the determining factor for specific actions, notably adoption (Article 21) and separation of a child from parents against their will (Article 9). (United Nations High Commissioner for Refugees [UNHCR], 2008) 
The application of the principle of the best interests of the child with its myriad interpretations has influenced practice in human rights law, family law, and child and family welfare, both nationally and internationally (Alston, 1994; Freeman, 2007; Goldstein, Freud, \& Solnit, 1973; Mnookin, 1975). The indeterminacy of the principle, the subjectivity of its application, and the implications of this across diverse cultures and contexts has received wide attention as part of the ongoing process (Alston, 1994; Freeman, 2007; Lynch, 2001; Ralph, 1998; Young, 2003).

The inherent subjectivity [of the application of the best interests test] renders it particularly susceptible to the criticism that it legitimises cultural bias, by allowing decision makers, who are generally members of the dominant culture to impose family values that may be inconsistent with those of a minority group, such as Aboriginal people. (Walter, Isnegger, \& Bala as cited in Ralph, 1998, p. 140)

The diversity of opinions on what is "good" for children is thus a common theme in the literature on this issue (Alston, 1994; An-Na'im, 1994; Freeman, 2007; Lynch, 2001; Parker, 1994; Ralph, 1998; Young, 2003). Mnookin (1975) summarised the dilemma as follows:

Deciding what is best for a child poses a question no less ultimate than the purposes and values of life itself. Should the judge be primarily concerned with the child's happiness? Or with the child's spiritual and religious training? Should the judge be concerned with the economic "productivity" of the child when he grows up? Are the primary values of life in warm, interpersonal relationships, or in discipline and self-sacrifice? Is stability and security for a child more desirable than intellectual stimulation? (Mnookin, 1975, p. 260)

Such questions will elicit diverse responses depending upon the values, beliefs, culture, and context of the respondents. In this sense, the indeterminacy of the principle is in many ways appropriate. According to Alston (1994), such indeterminacy was in fact a characteristic of international human rights standards that, by remaining vague and indeterminate, avoids rigidity and paralysis and instead allows the emphasis on both the importance of institutions in interpreting the principle and the importance of doing this in accordance with cultural and contextual factors. Parker (1994) argued that this is where the role of localised conventions and institutions within those localised contexts comes in, namely, to give substance to the understanding of the principle.

Application of the Best Interests Principle in Victoria

Current child and family welfare policy in Australia has done much to move away from its historic failure to protect or respond appropriately to Aboriginal children. The current Victorian legislation addresses the indeterminacy of the best interests principle by defining a set of best interests standards, which includes notions such as: the need to strengthen and preserve the family, the desirability of continuity and stability in a child's care arrangements and, significantly for Aboriginal children, the importance of the protection and promotion of their cultural identity and their connection to family 
and community (Children Youth and Families Act, 2005). Furthermore, the new practice framework, developed to support a consistent application of the standards, specifies the need for child and family welfare practitioners to attend to children's safety, stability, and development through the lens of their age, stage of life, culture, and gender. The legislation also specifies a number of additional decision-making principles particular to Aboriginal children including: (a) the need to protect and promote the cultural and spiritual identity and development of Aboriginal children and to maintain and build connections to their Aboriginal family and community; (b) adherence to the Aboriginal Child Placement Principle (ACPP), which specifies the order of priority when placing Aboriginal children in out-of-home care; and (c) adherence to the principle of Aboriginal self-determination, which specifies the involvement of Aboriginal agencies and the child's community in decision-making processes and allows the secretary of the Department of Human Services to transfer her functions and powers in relation to a Protective Order for an Aboriginal child to an Aboriginal Principal Officer of a gazetted Aboriginal agency.

As Bamblett and Lewis (2007) have highlighted, this Victorian legislation is in fact the first real attempt in Australia to develop a culturally competent service system built on the principle of Aboriginal self-determination. The challenge now is ensuring that these new reforms are practically applied and are translated into a culturally competent service system that truly meets the best interests of Aboriginal children.

\section{Rethinking the Best Interests of the Child for an Indigenous Context}

While there has been no other research in Australia that specifically examines Aboriginal perspectives on the best interests of the child, an increasing body of knowledge is developing in Australia, which suggests the urgent need for an in-depth examination of this perspective. The notion that cultural perspectives may influence an understanding of what is good for children is clear in a recent report on the wellbeing of Aboriginal children (Bamblett, Frederico, Harrison, Jackson, \& Lewis, 2009). Examining the growing body of literature that describes Aboriginal perspectives on wellbeing, Bamblett et al. (2009) identified a clear distinction between conventional understandings of health and wellbeing and the more holistic approach of Aboriginal cultures that sees the physical, emotional, mental, spiritual, and cultural health of both the individual and the community as inextricably linked. Therefore, as this report highlighted, definitions of the socioemotional wellbeing of Aboriginal children can extend from their connection to land to mainstream understandings of serious mental health issues. This distinction may affect what one looks for when trying to assess the best interests of an Aboriginal child.

However, other research both in Australia and internationally has focused on different interpretations of what one actually sees. For example, child-rearing practices, particular to the culture and context in which they are practiced, have been considered fundamental to any understanding of the best interests of the child (Alston, 1994; An-Na'im, 1994; Armstrong, 1994; LeVine \& Miller, 1990; Neckoway, 
Brownlee, Jourdain, \& Miller, 2003; Young, 2003). One comparative ethnographic study that focused on the differences between Aboriginal (in this case Nunga) and Anglo child-rearing highlighted the way in which Nunga families encourage the independence, self-regulation, and self-reliance of their children and imbue them with a sense of responsibility towards other members of the family, particularly younger siblings (Malin, Campbell, \& Agius, 1996). This study demonstrated the way in which some of these characteristics were negatively viewed by non Indigenous families. For example, if a young child briefly wandered out of sight of the mother, it was seen as neglectful by the non Indigenous mother, whereas from the Nunga mother's perspective, it was both a sign of trust of her child's capabilities and trust in the older siblings' ability to look out for their younger sibling, as well as an effective way of preparing her children for the realities of life. This example echoes the findings of the Bringing them Home report, which highlighted that while definitions of abuse are more easily applied across cultures, definitions of neglect are more subjective, malleable, and culturally particular (National Inquiry into the Separation of Aboriginal and Torres Strait Islander Children from their Families, 1997).

Another theme common in the literature is that of attachment, with a number of authors arguing that the collective nature of many Aboriginal families, coupled with the emphasis on independence and autonomy in child-rearing can influence the way in which Aboriginal children express attachment in their relationships (Lynch, 2001; Ralph, 1998; Yeo, 2003). This aspect again echoes studies internationally, which have argued that attachment theory has been wrongly assumed as being universal and has been applied uncritically across cultures (LeVine \& Miller, 1990; Neckoway et al., 2003). Furthermore, attention has been drawn to the hierarchy of values between attachment and affiliation. Ralph (1998) argued that in most child and family welfare decisions, attachment is given much greater prominence than affiliation. However, this goes against traditional Aboriginal child-rearing, where affiliation can be equally if not more valuable.

With the collective nature of Aboriginal family life clearly a common element of difference in all the examples cited, it is not surprising that the individualist underpinnings of the principle of best interests have been highlighted as a concern. Similar to findings among cultures that are structurally more collectivist in nature (Armstrong, 1994; Rwezaura, 1994), Lynch (2001) argued that any consideration of the best interests of an Aboriginal child must involve a consideration of both the "rights and interests of the child in his or her community and culture and the rights and interests of the Aboriginal community and culture in its children" (p. 535). As an example, the Indian Child Welfare Act of 1978 in the USA has recognised that "there is no resource more vital to the continued existence and integrity of Indian tribes than their children" (p. 537). Thus, the USA has a direct interest in not only protecting Indian children, but also promoting the stability and security of Indian tribes and families.

Finally, resoundingly clear in the literature are the specific needs of Aboriginal children as members of a minority community within an often racist society (Bamblett et al., 2009; Lynch, 2001; Malin et al., 1996; Ralph, 1998). Unanimous in its 
message, this literature focuses on the reality of racism towards Aboriginal children in Australia today, the importance of a strong cultural identity to counteract this, and, ultimately, the detrimental effect that the removal and the severing of ties between Aboriginal children and their families and communities has on both the child and their community.

As is evident from this brief overview of the literature related to the best interests of Aboriginal children, cultural perspectives on what is good for children and cultural factors that influence the daily realities of Aboriginal children may both have a significant influence on our understanding of relevant best interests. The current paper describes a study that attempts to give voice to Aboriginal child and family welfare practitioners on these particular best interests.

\section{Background and Aims of the Study}

The research described in this paper was undertaken as part of a final-year social work honours program undertaken by the authors (Sephton supervised by Long), following the completion of a social work field placement with the Victorian Aboriginal Child Care Agency (VACCA). During this placement, the author (Sephton) had been part of an organisational working group whose purpose it was to examine The Best Interests Framework for Vulnerable Children and Youth (Department of Human Services, 2007) and its appropriateness for application to Aboriginal children. Key issues identified were that: (a) while this framework guides practitioners to utilise a "lens of culture" when assessing a child's safety, stability, and development, there was little material available to articulate exactly what the use of a lens of culture may look like in practice, raising a similar dilemma to the indeterminacy of the best interests principle itself; and (b) the very existence of a "consistent" or "universal" framework for determining the best interests of the child posed important questions in regard to the principle of Aboriginal self-determination.

As two non Indigenous women were conducting the research, ensuring that objectives matched the needs of the community was essential to the study's integrity. In this respect, the research developed out of the established relationship between both authors and VACCA, and research objectives were guided by questions identified within the agency itself. The objectives of the study were to: (a) identify an Aboriginal perspective on the "best interests of the child" in Victoria; and (b) assess the applicability of the current Department of Human Services (2007) framework within an Indigenous context. As the lead Aboriginal communitycontrolled agency for Aboriginal child and family welfare in Victoria, VACCA was seen as a prime site for the research. With programs across child protection, family support services, placement services, and program and policy development, as well as strong values in maintaining the agency's Aboriginality, embedding culture into all aspects of service delivery, and most importantly working towards meeting the best interests of Aboriginal children throughout the State, the uniqueness of the service 
provided a key opportunity to undertake research to hear the voices of Aboriginal child and family welfare professionals.

\section{Method}

\section{Design and Sample}

As non Indigenous researchers, we selected a qualitative approach to ensure that the voices of the Aboriginal child and family welfare practitioners would be at the centre of the findings, and we designed the study to ensure that they were active participants in the research process. The study used purposive, judgment sampling, as it was aimed at accessing "information rich" cases with a specific knowledge-base (Rice \& Ezzy, 1999). The primary sampling frame was experienced Aboriginal child and family welfare professionals working at VACCA, who had been in the field for over three years and identified strongly with their Aboriginality. Six Aboriginal child and family welfare professionals voluntarily took part in the study. They were all current employees of VACCA and held a variety of positions, including direct practice and management across four different programs-Family Services, Link-Up, Aboriginal Child Specialist and Support Service, and the New Initiatives and Policy Unit. There was a gender balance with three females and three males, and participants ranged in age from their late 20 s to early 50 s.

\section{Procedure: Data-gathering and Analysis}

Individual semistructured interviews were conducted with each participant. Liamputtong and Ezzy (2005) described this type of interview as a meaning-making effort that is approached as a partnership between the researcher and participants. Thus, the interviews were a form of collaborative enquiry where participants were fully informed of the purpose, process, and intended outcomes of the study and were active subjects in the research process. Questions were designed primarily to be open, allowing participants to guide the conversation towards themes that they identified themselves. Initial open-ended questions covered three themes: participants' own description of the best interests of the child; the comparison of mainstream and Aboriginal perspectives on what is good for children, and their reflection on the Best Interests Framework for Vulnerable Children and Youth (Department of Human Services, 2007). Directive questions were also included where participants were asked to respond to ideas that had emerged from both literature and other participants.

The interviews were face-to-face, semistructured, and designed to resemble "deep conversations". They took between 1.5 and 2.5 hours and were audio-recorded and transcribed. Transcripts were analysed using a thematic, inductive data analysis process and, once organised into key issues and recurring themes, the data were presented to a focus group. While only three of the initial six participants were able to attend this group, all participants were given a summary of the themes that had emerged from the interviews and were asked to give feedback. The focus group 
considered the various themes that had emerged in the interviews, explored them in more depth, and drew out meaning together in response to the research questions. The focus group was also audio-recorded and transcribed. The final analysis involved a thorough examination of the data emerging from both interviews and focus groups and focused on the voices of the participants.

\section{Results and Discussion}

In presenting the findings from this study, voice is given to participants' perspectives on the best interests of the child. Each of the participants shared stories, both personal and professional, which highlighted and challenged a number of the themes already present in the literature. A sense of distinct cultural understanding of what was in the best interests of Aboriginal children emerged as they shared their perspectives. Approaches surfaced that, as one participant termed it, were "unique to the (cultural) Way" (P1). Quotations from a number of participants have been used selectively in this section to illustrate the overarching themes that grew out of their stories. Unless otherwise specified as an individual's or a number of individual's viewpoints, these themes were those that were confirmed by the three participants present at the focus group, and the individual feedback provided by other participants unable to attend the focus group.

\section{Affirming the Principle of the Best Interests of the Child}

In describing their perspectives on the best interests of the child, participants emphasised the universality of those most fundamental elements such as love, nurture, safety, stability, and care and spoke passionately about the importance of prioritising the child's needs above all else:

I think it makes it quite clear. I think it makes it easier because it means that you are not trying to satisfy competing needs because it is about the child, about the child's needs. What's best for the child and that's it. (P3)

The best interests of the child, as a child welfare service, we need to push that really hard. There should be no gimmies on any of that, it's just, we do it, we don't make any exceptions for anything. (P5)

Unlike literature that suggests that the individualist underpinnings of the principle could conflict with the beliefs and values of collectivist communities (Armstrong, 1994; Rwezaura, 1994), participants' responses demonstrated an uncompromising focus on the child with no intimation of discord between community values and an individualised attention on the child. Instead, participants highlighted the focus on the child as a core foundation of their cultural values and beliefs:

You belong to a family, you belong to a community and you have a very special and unique place in that community, you have a very special and unique place in your 
family....... Children are very much loved and valued. Little Bubs, and children, they come first. You know, you feed them first; you make sure they are alright. (P3)

In this way, participants made it clear that the general principle of the best interests of the child was given utmost regard in their work and the needs of Aboriginal children for those fundamental elements of care were much the same as for any other child. However, how these elements were assessed and the hierarchy of value given to each of these elements was much more complex, with each participant affirming that there were definitely "different eyes" when it came to the principles interpretation and application.

\section{In Their Own Words: Participants' Perspectives on the Best Interests of the Child}

In describing what was in the best interests of Aboriginal children, participants continually highlighted the need for a holistic approach, with the majority of participants $(n=5)$ directly criticising mainstream services for taking a narrow approach in understanding Aboriginal children's needs. Participants highlighted the need to understand each of the elements of a child's needs, not only in relation to the physical needs of children, but also their spiritual and cultural needs:

I guess the first thing is their physical safety, and then it's their spiritual safety, their cultural and emotional needs. So there is the physical and then there is the spiritual. (P3)

One way in which these cultural and spiritual needs were expressed by participants was the idea of children being given the opportunity to grow into and become themselves, that is, the importance of children knowing "where they're from", being "who they are", and becoming "who they are meant to be":

That the child grows in an environment that encourages and supports that child to reach their full potential....that they grow and they be the best that they can be, but they also be who they are, culturally, spiritually, who they are as a person. I mean you might have Aboriginal people, you might have Kuku Yalanji people, but for each person there's "the Way", and then there is their way of the "Way". (P1)

These understandings seemed to directly reflect aspects of Aboriginal childrearing practices and beliefs around the role of parenthood.

It's a nurturing way of bringing up children. You're not imposing what you want them to be, you're nurturing them to be who they are meant to be. (P3)

Notably, this notion of meeting the best interests of the child as the fostering of a child's "growth into themselves" is diametrically opposed to how one participant described the historical understanding and application of the best interests principle in Australia, an understanding that he highlights as still persisting today: 
It was a term that was abused for Aboriginal people. "For their own good" is something that, said wrong, Aboriginal people will resist........ because you are teaching me out of me, you are teaching me out of myself.......that's our history, yesterday they called it assimilation, as recent as 2007 they called it integration. The only way for Aboriginal people to move forward is to integrate into mainstream society. Whether you call it assimilation, integration, cultural mutilation, mind manipulation, it all equates to one thing, us not being us. (P1)

Thus, participants were all unequivocal in asserting the importance of a strong cultural identity, particularly in light of the pervasive racism and general absence of positive images of Aboriginal cultures and peoples in mainstream society today. For all participants, this was a reality that all Aboriginal children faced and from which they needed to be protected:

You wear it like a jacket; you think that other peoples' ideas of you is your reality. And because you don't have that cultural grounding or that support base you start to become like a shadow, where that negative stuff sticks more, and then changes your whole perception of you, and your people, and what you have to offer, and your worth.... and I see that all the time, they become these half people, like shadows. (P1)

\section{Different Eyes: Comparing Black and White Perspectives}

But there are different ways of working.......there are definitely different eyes. (P1)

Participants $(n=4)$ who had experience working in direct practice alongside mainstream services, shared stories of times when their perspective on what was in the best interests of a child differed. A number of participants $(n=3)$ spoke of times where they felt that behaviours or practices that were considered "normal" in their own families and communities were negatively perceived by mainstream services:

\footnotetext{
Some of those things (co sleeping, extended households, low on tucker) really come across when I was working in that job, because I'd be thinking oh dear, if you'd have come to my house, you'd probably be removing my kids....because that's just the way we did things....so I struggled with the department's perception on the way you're supposed to live. (P4)
}

Examples began to emerge with participants speaking about different approaches to sleeping arrangements, such as co sleeping even with children over two years, parents sharing bedrooms with younger children, and siblings and cousins sharing bedrooms or mattresses, or both. While participants shared their experiences of these sleeping arrangements being negatively perceived by mainstream workers, they highlighted them as positive parenting techniques that helped to establish attachments between the child and their family members. Similarly, participants spoke about the notions of "overcrowding," and the "parentification" of older siblings towards their younger siblings as common concerns of mainstream workers, whereas, 
in contrast, they themselves considered extended households and the teaching of responsibilities to older siblings as important tools for children's socialisation with kin and community and the development of their social and family responsibilities.

Although in identifying these differences participants strongly advocated greater understanding from mainstream services around these aspects of Aboriginal childrearing, it was also clear that participants were equally critical of a "black and white" approach, no matter which side of the black and white divide one was on. Identifying the complex layers of contemporary Aboriginal cultures today, participants described the way in which the many "poisons" (e.g., historical trauma, drug and alcohol abuse, racism) were impacting on many Aboriginal families today. For instance, co sleeping and extended households, when in accordance with the cultural Way, were seen as healthy and even in the best interests of children. However, where these poisons were impacting on this Way, risks were immediately identified:

I've had people put in notifications about overcrowding in houses ... but you've got to look at it in a cultural way. Our families, that's the normal thing, having a lot of people in the family home. Always that sharing and kinship care stuff. So you look at that in one way and think the kids can't do anything, but then you look at it in another way and think the kids are socially interacting with everybody ... but it's about unpacking risks and what is culturally appropriate. So, one family were smoking yarndi (marijuana) and drinking, up till all hours of the night, so, that's a risk, there is no cultural aspect of that, drinking and carrying on and smoking yarndi is not part of our culture. (P5)

Thus, what participants highlighted as essential was a careful examination, on a case-by-case basis, of the multitude of factors that can influence child-rearing practices in Aboriginal families. A broad understanding of Aboriginal child-rearing practices needed to be accompanied by:

- an understanding of, or preparedness to, listen to the Way of different Aboriginal cultural groups, the structures that surround these various ways, and the many protective factors that are inherent in them;

- an understanding of what one participant termed the "Wound" (P1), or in the words of another participant, the "introduced destroyers of culture" (P6), which have impacted on Aboriginal child- rearing today, including surface poisons (e.g., drugs and alcohol) and subsurface poisons (e.g., historical trauma), thereby creating a "bastardised culture" (P6), and;

- an understanding of how to assess the Way according to its appropriateness in the contemporary setting, looking at environmental factors (e.g., urban setting) and social factors (e.g., breakdown in the "collective" structure of many Aboriginal families. 
Distinguishing between the Way and the Wound, and between what is appropriate in a traditional setting and what is appropriate in an urban setting was therefore considered to be a large element in meeting the best interests of Aboriginal children. Participants felt that this posed a challenge for mainstream service providers, who, according to participants, generally did not have adequate knowledge of the Way and the protective factors that surrounded that Way. Take the case of the 14-year-old girl who is carrying the baby around: A lot of the observations from the protective workers are "Oh, that child is definitely parentified", but I say "Not necessarily; that behaviour aligns with the Way, as I know it" (P1). For participants, there was a clear distinction between behaviour that was based upon the Way in which the 14-year-old had been nurtured into her roles and responsibilities in looking after her younger siblings through the careful guidance of family members or, on the other hand, the Wound that forced her into taking on a "parenting" role due to her parents' inability to parent.

\section{Looking to Future Best Interests Through a "Cultural Lens"}

While participants spoke emphatically about the best interests of the child as the paramount consideration, the interconnectedness of child, family, and community were resoundingly clear in their interpretation of the best interests of the child. All participants felt strongly that ultimately it was in the best interests of the child to be with their family. Removing a child who is at significant risk was viewed as absolutely essential, and the emphasis on supporting families as much as possible with their parenting, finding placements within kinship networks, and keeping connections with kinship networks while placed elsewhere was clear. The need to work with whole families and communities was particularly highlighted in the context of the pervasive intergenerational trauma that has impacted on Aboriginal families. One participant described a case example of a family where each generation in the family, from the grandmother onwards, had been removed as children. In attending the funeral of one of the daughters, she recalled looking around the room and seeing "every welfare service you could think of" in the room - this was a young woman who had tried "absolutely everything" to give up the drugs and get her children back. However, also in the room, she noted were more people "chained up to somebody," and more prison vans than she had ever seen before. The layers of trauma were evident. As the participant described:

These were her networks, her supports, her friends, her family...she lived in an environment that was a risk to her... So the system, and way of working is to work only with her and her children but not to work with her brothers, sisters, aunts and uncles around her to protect her and I think that that way of working with families is not in the "best interests of children"... we really need to think more broadly than what's happening for mum and the child, but what's happening for grandma, and all those other supports. (P6) 
As well as the need to consider and work with family and community in meeting the best interests of children, there was also a clear and powerful feeling of an overarching drive that was based on a strong collective vision for the future of Aboriginal peoples:

I believe there can be a brighter day for Aboriginal peoples, I believe we do that through children, so we have to put in today, and plan for tomorrow, prepare for it. (P1)

This idea was reiterated again and again when exploring the importance of passing on culture. Not only was it seen as in the best interests of children, but also in the best interests of the future, given that Aboriginal cultures possess intrinsic values that should be maintained in their own right:

You have a sense of keeping your children safe because they are the future generation of our people. (P5)

In addition to their intrinsic value, participants also spoke about Aboriginal cultures as precious alternatives to contemporary Western cultures, criticising ongoing preoccupation with materialism, individualism, and the increasing isolation of people from any sense of community. Participants particularly highlighted the impact of these things on children and families, speaking of the intrusion of technology into family life, the increasing lack of respect from young people towards their Elders, and the increasing sexualisation of children in the media. With an unequivocal message that such a society was not their vision for the future of their peoples, the passing on of culture, and the development of physically, emotionally, culturally, and spiritually strong children was seen by many as a responsibility to be upheld by all, including children, for the future of Aboriginal peoples.

\section{Implications for Application of a Best Interests Framework in an Indigenous Context}

Although exploratory and limited in its scope, the present study has provided some important insights into the perspectives of Aboriginal child and family welfare professionals on the best interests of Aboriginal children. In identifying these perspectives and examining them within the context of the Victorian Best Interests Framework, it is clear that more work is necessary in developing this framework to meet the best interests of Aboriginal children. While the framework is certainly compatible with the perspectives of participants, it in no way captures the breadth and complexities of the best interests of Aboriginal children as shared by participants. Nor could it represent the vision and values of the Aboriginal professionals interviewed. The framework overtly specifies the need for a "cultural lens" to be used. But the examples, given by participants of the "different eyes" used in interpreting and applying the principle of the best interests of the child, highlight the urgent need for more emphasis to be placed on what it means practically to work 
with a cultural lens. Work is underway to achieving this end, with the introduction of the Victorian Aboriginal Cultural Competence Framework (VACCA, 2008). But a major challenge in fully accomplishing this approach is the lack of research in areas vital to its development (e.g., Aboriginal child-rearing, Aboriginal attachment patterns, and the impact of racism on Aboriginal children). Aboriginal professionals have continued to argue for cultural differences and needs to be acknowledged. However, without a concrete evidence-base to back up their voices, they continue to face the difficulties of proving their validity against a set foundation based on years of Western research.

A further challenge lies in capturing the complexities of working with a cultural lens. The present study reflects the minimal existing research on themes related to the best interests of the child. One striking feature is the way participants' responses reflected an intense awareness of diversity and complexity in working with Aboriginal children and families. Other literature has highlighted the collective attachment patterns of Aboriginal children (Yeo, 2003), the fluidity of child care arrangements in Aboriginal child-rearing (Lynch, 2001), and the emphasis on the independence and autonomy of Aboriginal children (Malin et al., 1996). Nevertheless, participants in this study were remarkably careful to avoid black and white statements; for instance, they provided examples of where fluidity of child care arrangements was in the best interests of the child and where, in other circumstances, it was incredibly detrimental to their wellbeing. If the use of a cultural lens is to be anything more than a token attempt at culturally sensitive practice, it is these complexities that need to be unpacked.

The development of knowledge in Aboriginal child-rearing, Aboriginal attachment patterns, and related areas can assist mainstream services to gain a greater understanding of the realities of Aboriginal children and the diversity of those realities, but this also has its limitations. If we are to truly recognise the principle of Aboriginal self-determination, then the use of a cultural lens must extend beyond mere understanding to a place where culture informs the way in which we actually value what is good for children. In this way, the notion of working with a lens of culture will have different meanings for mainstream service providers and Aboriginal community-controlled services. As demonstrated in participants' responses, there is most definitely a "lens" of each worker that is based on their own cultural affiliations and informs how the best interests of the child are determined.

For the Aboriginal professionals who participated in this study, the need for a holistic approach that focuses on the physical, emotional, cultural, and spiritual needs of the child was not represented in the Victorian Best Interests Framework for Vulnerable Children and Youth (Department of Human Services, 2007). Similarly the framework, while highlighting the role of family and community in the best interests of the child, could not represent the very particular importance of community within Aboriginal cultures. Some previous literature has suggested that the "individualistic" underpinnings of the best interests principles do not sit with more "collectivist" cultures (Armstrong, 1994; Lynch, 2001; Rwezaura, 1994). However, it was clear from 
participants that the focus on the individual child did not conflict with their cultural beliefs about the interconnectedness of child, family, and community. Rather, it confirmed the cultural belief that children are sacred and central to family and community. The very tangible reality, that without children there would be no future for Aboriginal peoples, clearly added an important layer to how the best interests of the child was understood. With these elements in mind, it is recommended that effort be given to supporting and promoting Aboriginal services to articulate and document these very particular perspectives on the best interests of the child, so that practice and future policy development can be informed more fully from this point on.

\section{Conclusion}

The present research project has identified some important perspectives in understanding what is in the best interests of Aboriginal children and has highlighted the way in which "different cultural eyes" may result in varying outcomes in applying the principle of the best interests of the child. These differences were not only informed by the different realities for Aboriginal children, but also by differences in what were seen as good for the children. Furthermore, it has drawn attention to the way in which the specific context of Aboriginal child and family welfare, with all the remnants of the trauma of colonisation, as well as the urge towards a decolonisation in which Indigenous peoples' "collective" rights to self-determination are upheld, added an important layer of understanding to the principle. This study can only provide part of the picture, but it is crucial that more research into the best interests of Aboriginal children is conducted. The history of the best interests principle and its application to Aboriginal children in Australia has been one of great pain and shame, where the principle was defined and applied by the dominant culture and Aboriginal perspectives were silenced. With the recent reforms to the child and family welfare system, a powerful opportunity to set right this historic imbalance has arrived. The wealth of knowledge and experience shared by Aboriginal child and family welfare professionals in this study provides a strong example of the potential for this change to occur, if we can just listen.

\section{Acknowledgements}

The authors would like to acknowledge Lance James, Bev Murray, Sylvia Terare, Nathan Fenelon, and Matthew Duggan for their invaluable contributions to this paper. Also very special thanks to Aunty Muriel Bamblett for her input and for opening the doors of the Victorian Aboriginal Child Care Agency for this research to take place. 


\section{References}

Alston, P. (1994). The best interests principle: Towards a reconciliation of culture and human rights. International Journal of Law and the Family, 8, 1-25.

An-Na'im, A. (1994). Cultural transformation and normative consensus on the interests of the child. International Journal of Law and the Family, 8, 62-81.

Armstrong, A. (1994). School and salsa: Custody and the best interests of the child in Zimbabwe. International Journal of Law and the Family, 8, 151-190.

Australian Institute of Health and Welfare. (n.d). Children and youth: Overview. Retrieved January 27, 2010, from http://www.aihw.gov.au/indigenous/community/child.cfm

Bamblett, M., \& Lewis, P. (2006). A vision for Koorie children and families: Embedding rights, embedding culture. Just Policy, 41, 42-46.

Bamblett, M., Frederico, M., Harrison, J., Jackson, A., \& Lewis, P. (2009). Not one size fits all: Measuring the social and emotional wellbeing of Aboriginal children. Unpublished manuscript, Melbourne: La Trobe University; Victorian Aboriginal Child Care Agency, Berry Street - Take Two. Berry Street - Take Two Program.

Bamblett, M., \& Lewis, P. (2007). Detoxifying the child and family welfare system for Australian Indigenous peoples: Self determination, rights and culture as the critical tools. First People's Child and Family Review, 3, 43-56.

Children Youth and Families Act 2005.

Department of Human Services. (2007). The best interests framework for vulnerable children and youth. Victoria: Department of Human Services.

D’Souza, N. (1993). Aboriginal child welfare: Framework for a national policy. Family Matters, 35, $40-45$.

Freeman, M. (2007). Article 3. The best interests of the child. In A. Alen, V. Lanotte, J. Verhellen, E. Ang, F. Berghmans, \& M. Verheyde (Eds.), A commentary on the United Nations Convention on the Rights of the Child (pp. 1-73). Leiden: Martinus Nijhoff Publishers.

Goldstein, J., Freud, A., \& Solnit, A. (1973). Beyond the best interests of the child. New York: The Free Press.

Indian Child Welfare Act, 1978.

LeVine, R., \& Miller, P. (1990). Strange situations in other cultures: An anthropological view of infant-mother attachment. Human Development, 33, 73-80.

Liamputtong, P., \& Ezzy, D. (2005). Qualitative research methods (2nd ed.). South Melbourne: Oxford University Press.

Lynch, P. (2001). Keeping them home: The best interests of indigenous children and communities in Canada and Australia. Sydney Law Review, 23, 501-542.

Malin, M., Campbell, K., \& Agius, L. (1996). Raising children in the Nunga Aboriginal Way. Family Matters, 43, 43-47.

Mnookin, R. (1975). Child custody adjudication: Judicial functions in the face of indeterminacy. Law and Contemporary Problems, 39, 226-293.

National Inquiry into the Separation of Aboriginal and Torres Strait Islander Children from their Families (1997). Bringing them home: Report of the national inquiry into the separation of aboriginal and Torres Strait Islander children from their families. Canberra: Australian Human Rights and Equal Opportunity Commission. Retrieved 11 May 2010, from http://www. hreoc.gov.au/social_justice/bth_report/report/index.html

Neckoway, R., Brownlee, K., Jourdain, L., \& Miller, L. (2003). Rethinking the role of attachment theory in child welfare practice with Aboriginal people. Canadian Social Work Review, 20, $101-115$.

Parker, S. (1994). The best interests of the child: Principles and problems. International Journal of Law and the Family, 8, 26-41. 


\section{M. Long \& R. Sephton}

Ralph, S. (1998). The best interests of the Aboriginal child in family law proceedings. Australian Journal of Family Law, 12, 140-149.

Rice, P. L., \& Ezzy, D. (1999). Qualitative research methods: A health focus. Melbourne: Oxford University Press.

Rwezaura, B. (1994). The concept of the child's best interests in the changing economic and social context of Sub-Saharan Africa. International Journal of Law and the Family, 8, 82-114.

United Nations (1989). Convention on the Rights of the Child. Office of the United Nations Higher Commissioner for Human Rights Convention on the Rights of the Child 1989. Retrieved 11 May 2010, from http://www2.ohchr.org/english/law/crc.htm

United Nations (1959). Declaration of the Rights of the Child. United Nations Declaration of the Rights of the Child (1959). Retrieved 11 May 2010, from http://www.un.org/cyberschoolbus/ humanrights/resources/child.asp

United Nations High Commissioner for Refugees [UNHCR] (2008). Guidelines on determining the best interests of the child. Retrieved 10 May 2010, from http://www.unhcr.org/refworld/docid/ 48480c342.html

Victorian Aboriginal Cultural Competence Framework [VACCA] (2008). Victorian Aboriginal Child Care Agency.

Yeo, S. S. (2003). Bonding and attachment of Australian Aboriginal children. Child Abuse Review, $12,292-304$.

Young, C. (2003). Best interests of the child: The directors of Indian child and family services speak. Canada: The University of Regina. 